\title{
Exploring Urban Renewal Strategies in China from a Humanistic Perspective
}

\author{
Wang, M.M., SHANGHAI TONGJI URBAN PLANNING \& DESIGN INSTITUTE CO.LTD, China
}

\begin{abstract}
From the perspective of humanism, this paper firstly discusses the value orientation of urban renewal, for whom the city is renewed, what is the ultimate goal of urban renewal, "People who walk on the sidewalk make the city", humanism is to return to the perspective of people, respond to the demands of people Then, using research methods such as systematic analysis, literature analysis and comparative analysis of cases, we sort out the relevant theories and case experiences of people-centredness and urban regeneration, study the association between people-centredness and urban regeneration, and use this as a basis to propose strategic responses and considerations for urban regeneration in China.

Urban regeneration in China has been extensively studied by a number of scholars, with the focus mostly on the physical environment. This paper focuses on expanding the study of people-centred strategies in the urban regeneration process and proposes regeneration strategies to protect and promote human development, including strategies to ensure fairness and justice in regeneration, to meet the needs of people's livelihood and sense of security, and to promote human development.
\end{abstract}

\section{Keywords}

humanism, urban renewal, human development, vitality

\section{Background}

\subsection{China faces new challenges in new phase of urbanization}

According to China's seventh national census, the urbanisation rate of China's resident population will reach 63.89\% in 2020 (Ning 2021), already entering the middle and late stages of the urbanisation process. According to the general rules of urbanisation in the world, the growth rate of urbanisation will slow down relatively soon and China is facing the choice of the "Y" path of urbanisation (physical urbanisation/intellectual urbanisation) in the world; before reaching the critical point of $65 \%$ urbanisation rate (After the urbanisation rate reaches $50 \%$, the development paths of countries around the world start to diverge due to the different development conditions; the key point in determining the two paths is around $65 \%$ of the urbanisation rate; the intellectual urbanisation path represented by developed countries such as the United Kingdom, France, Germany and Japan jumped around 65\% of the urbanisation rate, with rapid economic growth and entered the development path of an innovative country; in the case of the physical urbanisation countries represented by Brazil, the society hovers between imitation and replication due to the lack of intellectual and capital support and the lack of innovation capacity at $65 \%$ of the urbanisation rate), China must substantially improve the input, main body and output elements of intellectual development of urbanisation, so as to lay a solid foundation for intellectual urbanisation. This 
will lay a solid foundation for the path of intellectual urbanisation and help China to become an innovative country (Wu 2015).

According to a study by the China Development and Reform Commission, China's urbanisation rate is expected to enter a relatively stable state at around $75 \%$, with the growth rate expected to decline further after reaching $70 \%$ in 2035. In particular, during China's 14th Five-Year Plan period, the new type of urbanisation is facing serious challenges (Zhang 2021), including a continuous slowdown in the growth rate of urbanisation, a concentrated outbreak of urbanisation problems (big city disease, urban fragmentation, shrinking cities), and "reverse urbanisation" (population shifting from big cities to neighbouring The challenges include the continued slowdown of urbanisation growth, the concentrated outbreak of urbanisation problems (big city disease, urban fragmentation, shrinking cities), the "reverse urbanisation" (the return of population from big cities to surrounding small and medium-sized cities, and from small and medium-sized cities to rural areas), the accelerated fragmentation of urban patterns, and the transformation of urbanisation mechanisms.

In the face of this growing situation, the "Outline of the 14th Five-Year Plan for National Economic and Social Development of the People's Republic of China and Vision 2035", published this year, clearly states that "the new urbanisation strategy with people at its core will be promoted in depth" and that the transformation of the urban development mode will be accelerated. "implement urban renewal actions". The new concept of building cities with a people-centred approach and the new trend of promoting the optimisation of urban spatial structure and quality enhancement through urban renewal have been made clear at the national strategic level. The question of the choice of path for China's urbanisation is answered at the level of national policy.

\subsection{Chinese people's interest in 'urban regeneration' continues to rise}

The internet search popularity and demand for "urban renewal" over the past decade (2011-2021) shows that the Chinese public's interest in "urban renewal" has continued to rise, especially in the core hotspots of "old Urban renewal" has continued to increase in popularity among the Chinese public, especially in the core hotspots of "renovation of old districts", "renovation of shantytowns", "double-cultivation of cities" and "urban design". From actual cases in recent years, urban regeneration has gradually moved away from the "concrete jungle" of "big demolition and big construction" to focus on redeveloping old neighbourhoods, preserving local cultural characteristics, and attracting, gathering and retaining people, rather than image. Therefore, the strategy of paying attention to people in the process of urban regeneration is of great relevance.

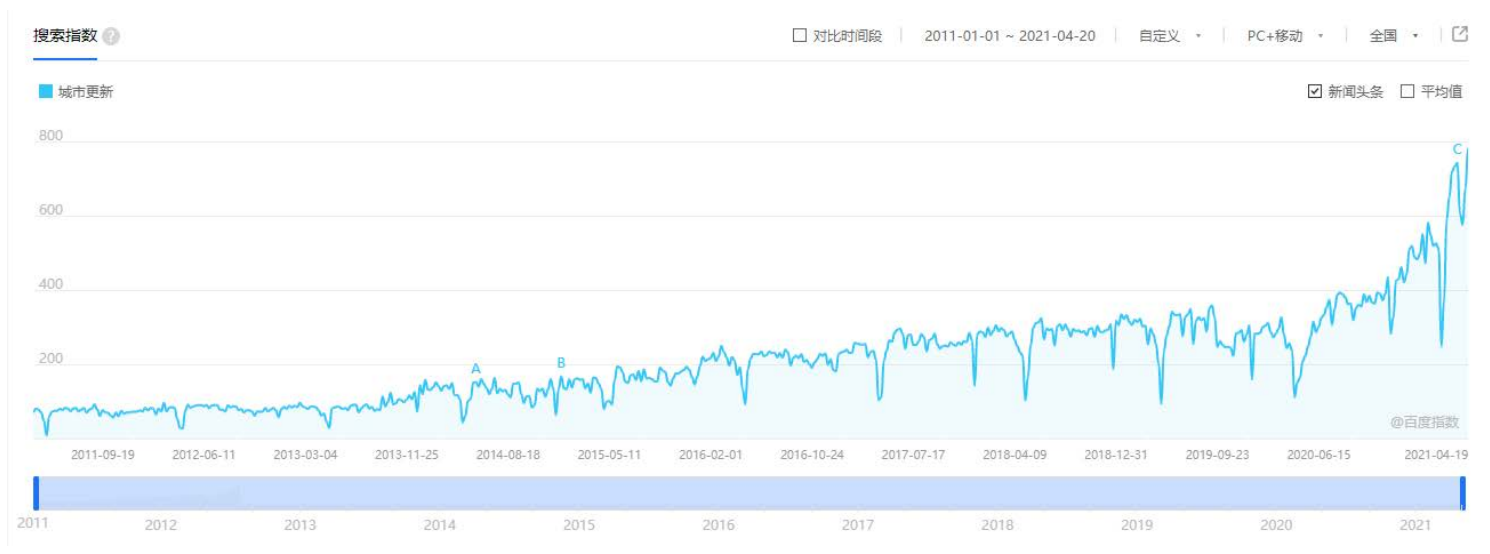

Figure 1. Illustration of "urban renewal" search index in China (2011 - 2021). Source: Baidu Index. 


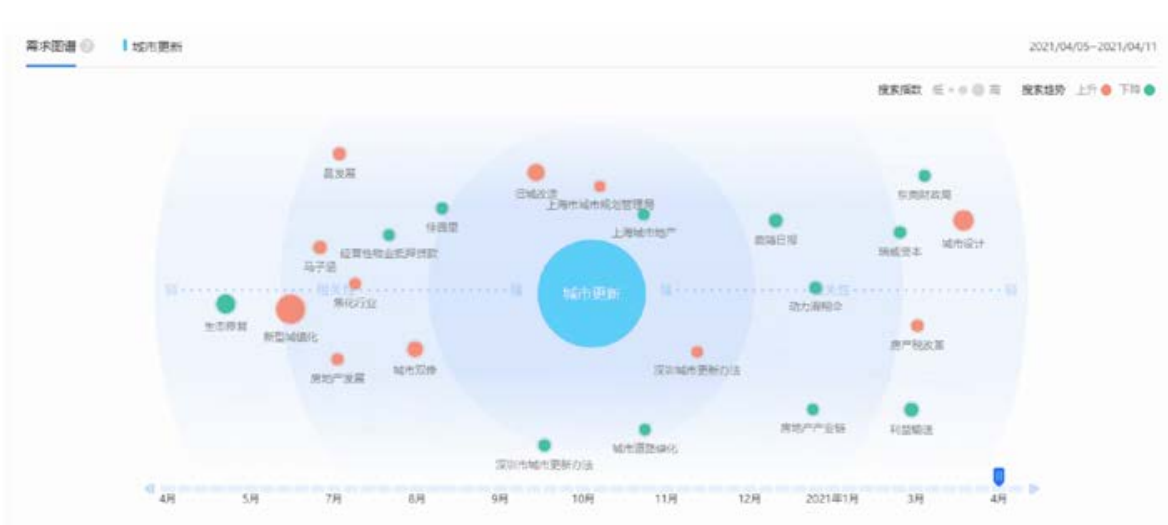

Figure 2. Illustration of "urban renewal" search demand mapping in China (April 2021). Source: Baidu Index.

Therefore, in the context of the major transformation of the urban social structure brought about by rapid urbanisation and the shift from 'incremental expansion' to 'stock renewal' in large and medium-sized cities, the study of urban regeneration in China has gradually become a hot topic. A number of Chinese scholars have conducted extensive research on urban regeneration, but the focus has mostly been on the physical environment. Based on this, we propose a humanistic approach to urban regeneration from the perspective of China's national strategy and the concerns of the Chinese people, in order to propose a response and reflection on urban regeneration strategies that take into account the interests of the people.

\section{The value proposition of urban renewal}

Since the industrial revolution, urban regeneration has been one of the most important topics of urban planning research in the world, and an inevitable concern after urbanisation has reached a certain stage. Throughout the development of urban regeneration in the world, from the early post-World War I 'bulldozer redevelopment', to welfare-coloured community regeneration and market-oriented redevelopment of old cities, to community regeneration that takes into account the physical environment, economic and social dimensions (Dong 2009), the focus of urban regeneration has gradually transitioned from slum clearance and upgrading the physical image of cities to revitalising the economic vitality of old cities. The focus of urban regeneration has evolved from slum clearance and upgrading the physical image of the city to revitalising the economic vitality of the old city, and then to a comprehensive community regeneration that emphasises the human environment, the preservation of the historical values and the maintenance of the fabric of the community, and through a combination of top-down and bottom-up approaches.

In the third decade of the 21st century, the answer to the question of who the city is for and what the ultimate goal of urban regeneration is is becoming clear. "People who walk on the sidewalk make the city". People who walk on the sidewalk make the city", said Aristotle, "People gather in the city to live and stay in the city to live better". The city is a people's city, a people-centred city; urban regeneration is the continuous improvement of urban space and functions in order to create a happier and better life for the people.

In other words, the starting point of urban regeneration - humanism. Firstly, it returns to the perspective of people and responds to their aspirations. Early urban regeneration aimed to solve urban problems, but often neglected the close connection between people and the city. A humanist perspective may not necessarily solve urban problems directly, but it can deduce the causes of urban problems and provide a basis for accurate urban decision-making. Secondly, it addresses the diverse needs of individuals and society. Modern urban regeneration participants and stakeholders include government departments, the private sector, community residents and other organisations, etc. Adopting a multi-party collaborative approach to meet the diverse needs of individuals and society through integrated measures and 
overarching regeneration pathways is an effective means of upholding humanism and sustainable development.

\section{Strategic responses to urban regeneration}

\subsection{Ensuring fairness and justice in regeneration}

Some (or even many) urban regeneration in China is still dominated by power and capital, and the weakness of civil society makes it difficult to form effective checks on power and capital. Therefore, balancing the game between citizens, government and the market, and achieving parity of discourse between the three, has become the key to fairness and justice in urban regeneration. For example, in the urban regeneration of Tianzifang in Shanghai, the indigenous people have shown almost unprecedented enthusiasm and continued participation in the urban regeneration (Extremely rare in the historical process of urban regeneration in China). In order to develop the economy while preserving the original memory of the place, and to protect the original atmosphere of daily life, the memory of the place and the scenery of the place, the indigenous people of Tianzifang have awakened to their own consciousness and actively participated in the decision making and management of urban regeneration and development, helping to transform Tianzifang from a group of alleyway factories in the middle of the city into a cultural and creative business card of Shanghai (Zhu 2015), providing a model for the subsequent urban regeneration of the role of the residents. It provides a model for subsequent urban regeneration.

Urban regeneration, which should be shaped by the integrated role of government, market and society, should protect the social-ecological system and guide the synergistic development of the city's economy, environment and society. The establishment of a public participation and coordination mechanism covering the government, community residents, incoming organisations and businesses is a guarantee of fairness and justice in urban regeneration. On the one hand, innovate the institutional mechanism of urban regeneration. In the context of building an ecological civilisation, it is further clarified that ecological civilisation is a new type of civilisation that is humanistic and guarantees fairness and justice; repairing social conflicts and social crises that have accumulated due to the long-term emphasis on economic development and limited efficiency is one of the key strategic objectives of urban regeneration. On the other hand, in conjunction with the construction of an innovative social governance pattern of joint construction and sharing, the government can guide community residents, incoming organisations and businesses to actively participate in urban and community regeneration affairs, encourage community residents and others to participate in community management, jointly promote the smooth implementation of urban regeneration, and jointly maintain the subsequent operation of urban regeneration.

\subsection{Meeting the needs of human life and security}

Improving the living environment, enhancing the quality of life and meeting the need for a sense of security are the basic principles of urban regeneration. It is important and far-reaching for promoting the optimization of urban structure and quality improvement, and promoting sustainable and healthy social development. "A city's historical sites, cultural monuments and human heritage are part of the life of the city." Through the preservation of local culture and "human scale" design, the city's "smoke and mirrors" are preserved, providing a warm space of urban memory and humane space. In the newly promulgated Shanghai Urban Renewal Regulations (to be implemented on 1 September 2021), it is clearly stated that urban renewal should be based on the principle of "preservation, transformation and demolition". The preservation of town patterns, streets and alleys, and individual buildings will help to preserve the city's historical heritage and living memory. 
For example, the Kuanzhai Alley in Chengdu is a famous example of the preservation, restoration and renewal of a historical and cultural district. In the conservation and regeneration of Chengdu's Kuanzhai Alley, the texture, scale and texture of the area have been kept unchanged, thus preserving the original rich form and perpetuating the atmosphere of urban life. The width of the streets is about 7 metres for the wide lanes and 5 metres for the narrow lanes, while the buildings along the streets are 1-2 storeys and about 5-8 metres in height, forming a pleasant spatial scale of 'a hundred feet for the shape and a thousand feet for the potential'. Kuanzhai Alley is not only a cultural card of Chengdu, but also a classic example of urban regeneration to be promoted and studied nationwide.

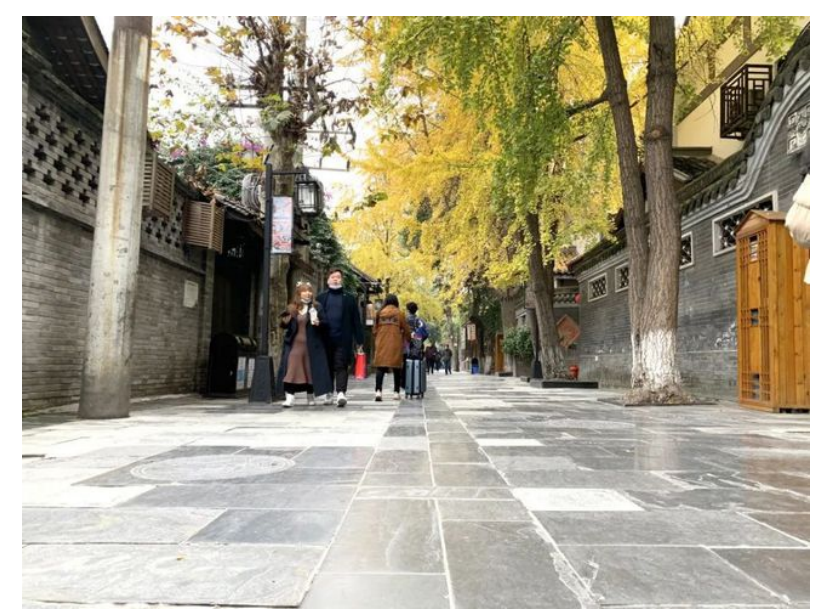

Figure 3. Kuanzhai Alley in Chengdu - Broad Alley. Source: https://www.163.com/dy/article/FU48U9UV05458NMX.html.

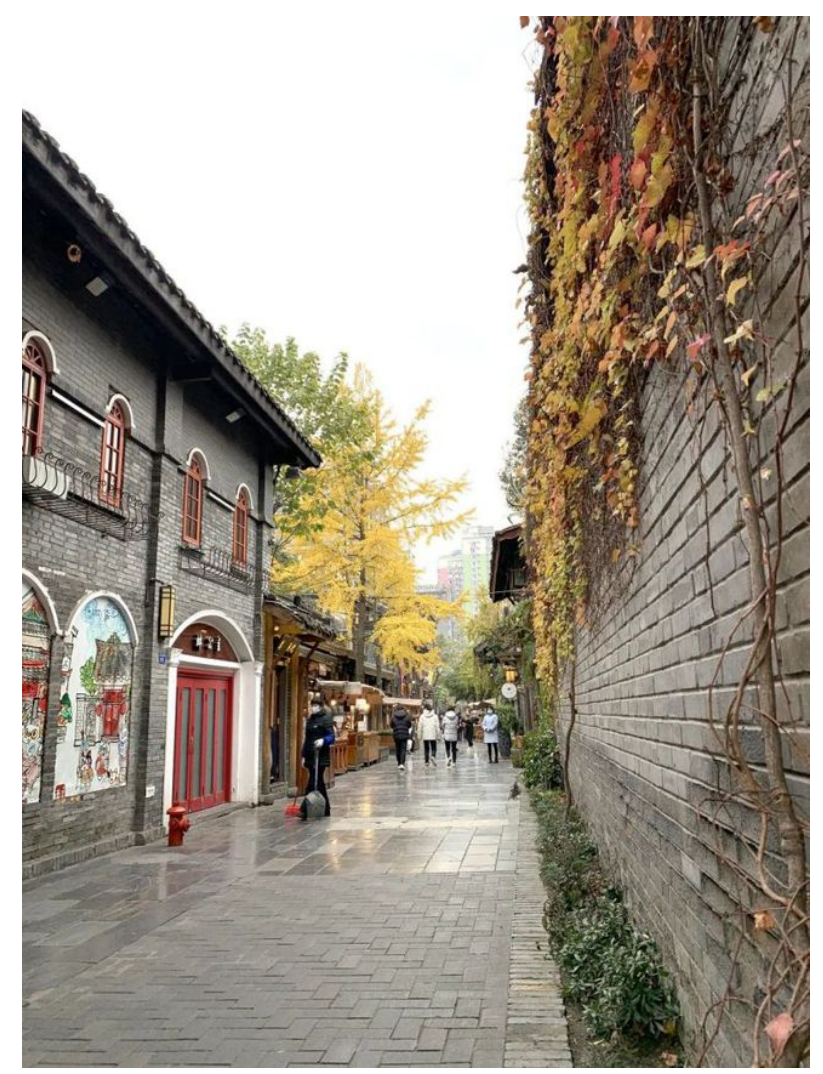

Figure 4. Kuanzhai Alley in Chengdu - Narrow Alley. Source: https://www.163.com/dy/article/FU48U9UV05458NMX.html. 


\subsection{Promoting human development}

Yang Baojun, Chief Economist of China's Ministry of Housing and Urban-Rural Development, has pointed out that, the city is a source of innovation, gathering rich innovation resources, and urban residents are the core innovation subjects. The introduction of intellectually driven professional service industries, the clustering of knowledge-intensive industries and the development of the district driven by intellectual industries, knowledge services and supporting services is one of the effective ways of urban regeneration at the district level. Knowledge-intensive industries have high added value, fast growth rates and high cultural and technical levels of practitioners, especially information services (e-commerce, communication services, big data processing, database services, etc.), R\&D services (natural science and technology R\&D, engineering and technology R\&D, humanities and social science research, etc.), technical services (engineering design services, industrial design services, craft design services, etc.), cultural The development of knowledge-intensive industries and the injection of an intellectual engine to stimulate the renewal of regional vitality will not only enhance regional industrial capacity, but also promote the allround development of people and the realisation of their values.

For example, the urban renewal of Guangzhou Liwan Julongwan Area (being implemented), the transformation of state-owned enterprises to drive the transformation of old factories, old cities and villages in succession, Liwan Julongwan Area benchmarked against Shenzhen Bay, Financial City, Pazhou West, combined with the ecological and historical and cultural resources advantages of the site, responding to the future urban development needs of hyperspace, digitalisation, intelligence and sharing economy, to create a multi-functional integration, three-dimensional space open, shared facilities The site is a 100billion-grade wisdom valley industrial base, with intelligent services, technology and humanities intermingled. It includes new industries and economies such as trade and commerce services and production services, and realises the common development of people and the city. 


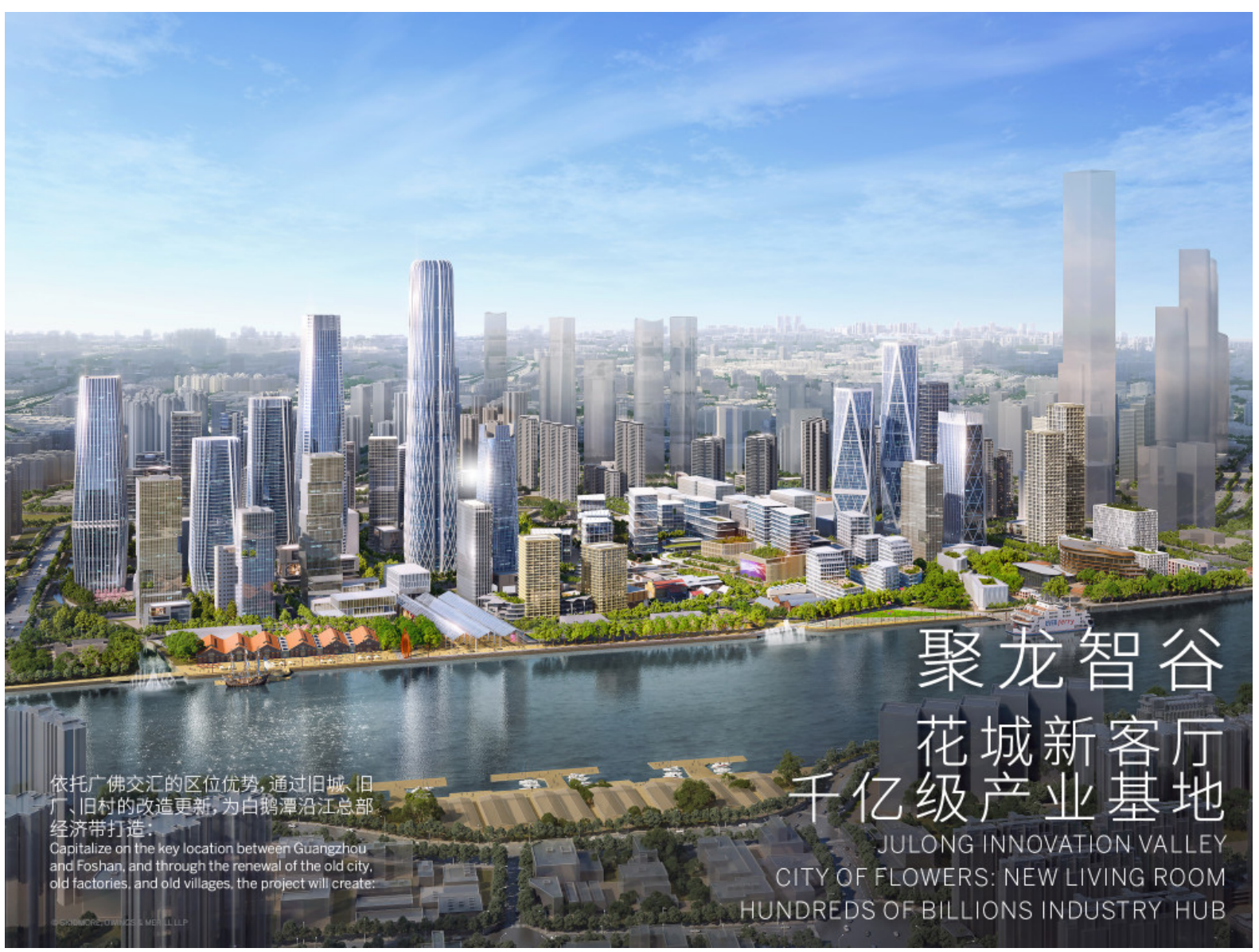

Figure 5. Guangzhou Julong Bay Area Renewal Plan. Source: https://new.qq.com/rain/a/20210331A03K7Y00

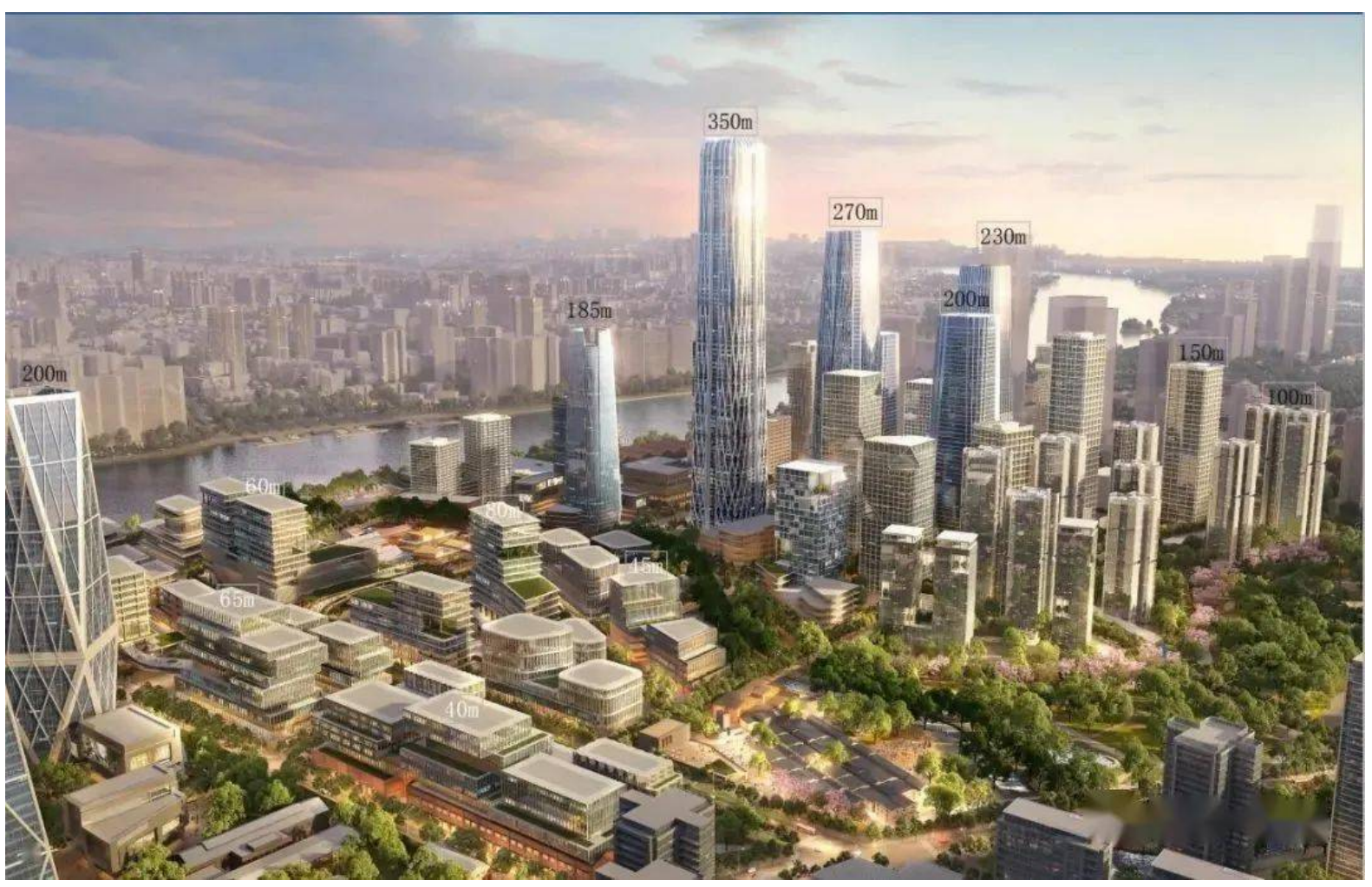

Figure 6. Guangzhou Julong Bay Area Renewal Plan. Source:

https://www.sohu.com/a/445309178_100020178 


\section{Conclusion}

This paper discusses the values of urban regeneration from a humanist perspective, and proposes three responses to urban regeneration: to ensure fairness and justice in regeneration through the establishment of a public participation and coordination mechanism involving the government, community residents, resident organisations and businesses; to meet the needs of human life and security through the preservation of local culture and 'human scale' design; and to promote human development by introducing and presenting intellectual service industries, injecting intellectual engines and stimulating the vitality of regenerated areas.

Louis Mumford said that a city is a theatre of social activity. In this paper, we hope that the regenerated environment will not only be a new building, landscape and site, but also a spatial upgrade and a continuation of activities that meet the diverse needs of society and people, carry cultural memories and present a sense of life.

\section{References}

Dong, M.L., Chen, T., Wang, L.Y. (2009)' History and policy evolution of urban renewal in the west', Human Geography, 24(5), p42-46.

Hou, X.L., Guo, H. (2018) 'Community micro-renewal: exploring design interventions for public space in beijing's old city', Landscape Architecture, 25(4), p41-47.

Lu, J.W., Wang, W. (2016) 'Characteristic vibrant district construction - an important strategy for urban renewal', Urban Planning Forum, 59(6), p101-108.

Liu, S.L. (2020) 'People's city: theoretical origin and contemporary development', Social Science in Nanjing, 20(8), p66-72.

Long, Y., Ye, Y. (2016) ' Human-scale urban form: measurements, performances, and urban planning \& design interventions', South Architecture, 35 (5), p41-47.

Ning, J.Z. (2021) 'Key data of the seventh national population census', national bureau of statistics, 10 May. Available at: http://www.stats.gov.cn/tjsj/zxfb/202105/t20210510_1817176.html (Accessed: 3 September 2021)

The Central People's Government of the People's Republic of China. (2021)' outline of the fourteenth five-year plan and vision 2035 for national economic and social development of the people's republic of china', Available at: http://www.gov.cn/xinwen/2021-03/13/content_5592681.html (Accessed: 3 September 2021)

Wang, M.W. (2021) 'Implementing urban renewal initiatives', Ministry of Housing and Urban-Rural Development of the People's Republic of China (MOHURD). Available at: http://www.mohurd.gov.cn/jsbfld/202011/t20201117_248050.html (Accessed: 2 September 2021)

Wang, S.F., Yi, Z.K. (2021) 'Urban regeneration led by institutional innovation', Shanghai Urban Planning, $30(4), \mathrm{p} 9-16$.

Wu, Z.Q., Yang, X. and Liu, W. (2015) ' Intelligent urbanization or labor urabanization: strategic thinking on urbanization path of china', Urban Planning Forum, 58(1), p15-23.

Yazar, M., Hestad, D.and Mangalagiu, D. et al. (2020) 'From urban sustainability transformations to green gentrification: urban renewal in Gaziosmanpaşa, Istanbul', limatic Change, 43(8), p637-653 
Yang, Y.H. (2019). China Human Development Report Special Edition, China Translation Press, China: Beijing.

Yang, J.Q. (2017) 'Urban Center Renewal and Redevelopment: A Holistic Thinking Based on the Concept of People-oriented and Sustainable Development', Shanghai Urban Planning, 26(5), p1-6.

Yang, J.Q. (2017) 'How citation changed the research world', The Mendeley, 62(9), p70-81.

Zhu, D.H, Huang, C.H. (2015) 'From "Margins" to "Subjects"_Reflections on the Changing Role of Indigenous People in the Context of Urban Renewal: Shanghai Xintiandi and Tianzifang as Examples', Architecture and Culture, 11(8), p172-173

Zou, B. (2015) 'The transformation from greenfield-based planning to redevelopment planning:theoretical analysis and practical strategies', Urban Planning Forum, 12(8), p12-19.

Zhang, H. (2021)'China's urbanisation problems are set to explode in concentration How can migrant workers enjoy the same treatment as citizens?', Caijing Magazine, 22 April. Available at: https://new.qq.com/omn/20210422/20210422A0BY1600.html (Accessed: 1 September 2021)

Zhang, J.C., Hu, Y. (2012) 'Critique of Urban Renewal in Transitional China Based on Socio-spatial Justice', Planner, 27(12), p5-9.

Zhang, J.X., Chen, H. (2014) 'Spatial Governance: Political Economy of China's Urban and Rural Planning Transformation', City Planning Review, 37(11), p9-15.

Zhuang, Y. (2021) 'Element and Relationship Reflection on the Key Issues in the Practice of Contemporary Urban Design', Time+Architecture, 37(5), p16-21. 